\title{
Medical debulking with gonadotrophin-releasing hormone agonists to facilitate vaginal hysterectomy
}

\author{
Joan Melendez • Ravi Bhatia • Abiodun Fakokunde • \\ Wai Yoong
}

Received: 9 June 2011 / Accepted: 17 July 2011 /Published online: 29 July 2011

(C) Springer-Verlag 2011

\begin{abstract}
Although the superiority of vaginal compared to abdominal hysterectomy is well established, most gynaecologists still prefer the abdominal route for removal of benign large uteri $>14$ weeks. Gonadotrophin-releasing hormone agonists such as goserelin can reduce uterine bulk by up to $60 \%$ and was initially used to convert a midline to Pfannenstiel incision in abdominal hysterectomy. The conversion of an abdominal to a potential vaginal hysterectomy by uterine size reduction would prove advantageous, and the authors present data from a case control study of 12 women with uteri $>14$ weeks who successfully underwent vaginal hysterectomy following preoperative treatment with goserelin. Women scheduled for hysterectomy for menorrhagia with non-prolapsing clinical uterine size of $>14$ weeks were offered an attempt at vaginal hysterectomy after pre-treatment with goserelin. A group of women with comparable uterine size who underwent abdominal hysterectomy for similar indication served as control. Pre- and postoperative data such as haemoglobin, myoma size, uterine weight, duration of procedure and complications were collected prospectively. Both groups had comparable preoperative haemoglobin, subjective preoperative uterine bulk (median 16 weeks) and body mass index. The vaginal hysterectomy group received a median of two goserelin injections prior to surgery, and the uterine weight at histology was similar in both groups (median 580 vs $609 \mathrm{~g}, p<0.05$ ). The duration of surgery was twice as long in vaginal compared to abdominal hysterectomy (153.7 vs $85 \mathrm{~min}, p<0.05$ ), but analgesia
\end{abstract}

J. Melendez $\cdot$ R. Bhatia $\cdot$ A. Fakokunde $\cdot$ W. Yoong $(\triangle)$

Department of Obstetrics and Gynaecology,

North Middlesex University Hospital,

London N18 1QX, UK

e-mail: wai.yoong@nmh.nhs.uk use and the length of inpatient stay were lower in the study group ( 2.62 vs 3.5 days, $p<0.05$ ). In women with $>14$ weeksize uteri, treatment with gonadotrophin agonists reduces uterine size sufficiently to allow safe vaginal hysterectomy. Although duration of surgery was longer, women who underwent vaginal hysterectomy required less analgesia and had shorter inpatient stay.

Keywords Vaginal hysterectomy · Medical debulking · Gonadotrophin-releasing hormone agonist

\section{Background}

Laparotomy is still the preferred route of surgical access in women requiring a hysterectomy for menorrhagia or fibroid, although it is well documented that intraoperative and postoperative morbidity, analgesia use and hospital stay are significantly lower with the vaginal route [1-4]. The abdominal route could be attributed to personal preference as well as lack of training and experience, and should vaginal hysterectomy ( $\mathrm{VH}$ ) become more widespread, the potential for cost saving and improved patient experience is significant: one study already demonstrated that the cost of abdominal and laparoscopic hysterectomy were $34.5 \%$ and $72 \%$ respectively higher than for vaginal hysterectomy [5].

The most common reason cited by gynaecologists for favouring abdominal over the vaginal approach is large uterine bulk, and many would be reluctant to attempt $\mathrm{VH}$ in patients with an estimated uterine size of 12-14 weeks [6, 7]. Observational and comparative studies by Magos et al. [8], Harmanli et al. [5] and Sahin [9], however, all demonstrate that uteri of up to 20 weeks could be removed vaginally. Interestingly, contrary to accumulating evidence supporting the vaginal approach particularly for this group, 
the American College of Obstetrics and Gynecology recommends against vaginal hysterectomy for women with uterine size of $>12$ weeks.

That the "average practicing gynaecologist, through deliberate effort, could increase his/her VH rate to $95 \%$ within 5 years" [10] was a great motivation for us as was the challenge of developing the confidence to progressively increase the size of the uteri that could be removed through the vaginal route (only $3.9 \%$ of hysterectomies for fibroid uteri were performed vaginally [11]).

Stoval and colleagues have used gonadotrophinreleasing hormone $(\mathrm{GnRH})$ agonists as a preoperative adjunct to medically debulk uteri, thus enabling hysterectomy, which otherwise would have been approached abdominally, to be performed vaginally [12].

In this study, we present data from a prospective case control study of 12 women with enlarged uteri without prolapse who were treated with a GnRH agonist in order to facilitate vaginal hysterectomy; the control group comprised patients with enlarged uteri who underwent total abdominal hysterectomy (TAH) for a similar indication (i.e. menorrhagia).

\section{Materials and methods}

This was a prospective case control study undertaken in a teaching hospital in London over a 2-year period. Between 2006 and 2008, women scheduled for hysterectomy for menorrhagia with clinical uterine size of $>14$ weeks were offered an attempt at $\mathrm{VH}$ after pre-treatment with goserelin acetate. Women in the study group received either one or two intramuscular doses of $3.6 \mathrm{mg}$ of goserelin (Zoladex, Astra Zeneca, Ltd.) while a group of women with comparable uterine size who underwent TAH for menorrhagia served as control; this study therefore achieves Oxford level II evidence. Oophorectomies were not routinely performed in either group.

VHs were performed by two consultant gynaecologists (WY and AF) who were experienced at doing the procedure for prolapse (as part of the repertoire of most trained gynecologists) but were attempting to gain more experience at removing larger non-prolapsing uteri $>14$ weeks through the vaginal route. TAH in the control groups was performed by consultant gynaecologist colleagues of the two senior authors or senior trainees under their direct supervision. All patients received an intravenous bolus dose of $1.2 \mathrm{~g}$ Augmentin intraoperatively and wore antiembolic stockings and/or sequential compression stockings. VH patients had a vaginal pack and indwelling urinary catheter in situ until the following morning. Postoperative pain management included oral narcotics, non-steroidal anti-inflammatory medications and, in addition, patient-controlled analgesia for the first day in the TAH group.

Patient characteristics such as age, ethnicity, parity, body mass index (BMI), uterine size on scan and clinical size at surgery, preoperative administration of GnRH analogues, histological uterine weight and histopathology report were recorded. Peri-and postoperative complications (including surgical, blood transfusion and pyrexia) and other important outcome measures such as change in haemoglobin concentration, operative time and length of postoperative hospital stay were also compared.

\section{Findings}

Prospective data from 12 patients were collected from the study and control groups, respectively. The two groups had statistically comparable median age (49 vs 48 years), pretreatment uterine length on ultrasound scan (12.1 vs $10.5 \mathrm{~cm})$, preoperative haemoglobin $(12.8$ vs $12.6 \mathrm{~g} / \mathrm{dl})$ and BMI ( 31.72 vs $\left.24.25 \mathrm{~g} / \mathrm{m}^{2}\right)(p>0.05$ in all cases). Women who had VH had higher parity than women who underwent TAH (3 vs 1.5, $p<0.05$ ) (Table 1).

The median subjective uterine size of the $\mathrm{VH}$ group prior to goserelin injections was 18 weeks (range 15-20 weeks), while the subjective uterine bulk at the time of surgery (median 16 vs 16 weeks) and histological uterine weight (median 580 vs $609 \mathrm{~g})$ were comparable in both groups $(p>0.05)$ (Fig. 1). The subjective median decrease in clinical uterine bulk was thus $11.11 \%$.

The median duration of surgery (137 vs $81.6 \mathrm{~min}$ ) and estimated blood loss (629 vs $422 \mathrm{ml}$ ) (both $p>0.05$ ) were significantly higher in the vaginal compared to the abdominal hysterectomy group, but this was skewed by

Table 1 Patient characteristics $N S$ not significant
${ }^{*} p<0.05$ is taken to infer statis-
tical significance

\begin{tabular}{llll}
\hline Patient characteristics & $\begin{array}{l}\text { VH }(n=12) \\
\text { Median (range) }\end{array}$ & $\begin{array}{l}\text { TAH }(n=12) \\
\text { Median (range) }\end{array}$ & $p$ value $^{*}$ \\
\hline Age (years) & $49(41-51)$ & $48(39-51)$ & NS \\
Parity & $3(1-4)$ & $1.5(0-4)$ & 0.04 \\
Uterine length on USS (cm) & $12(9-16)$ & $10.65(8-14)$ & NS \\
Clinical size at time of surgery (weeks) & $16(12-22)$ & $16(12-22)$ & NS \\
Previous abdominal surgery & $1 / 12$ & $2 / 12$ & NS \\
\hline
\end{tabular}




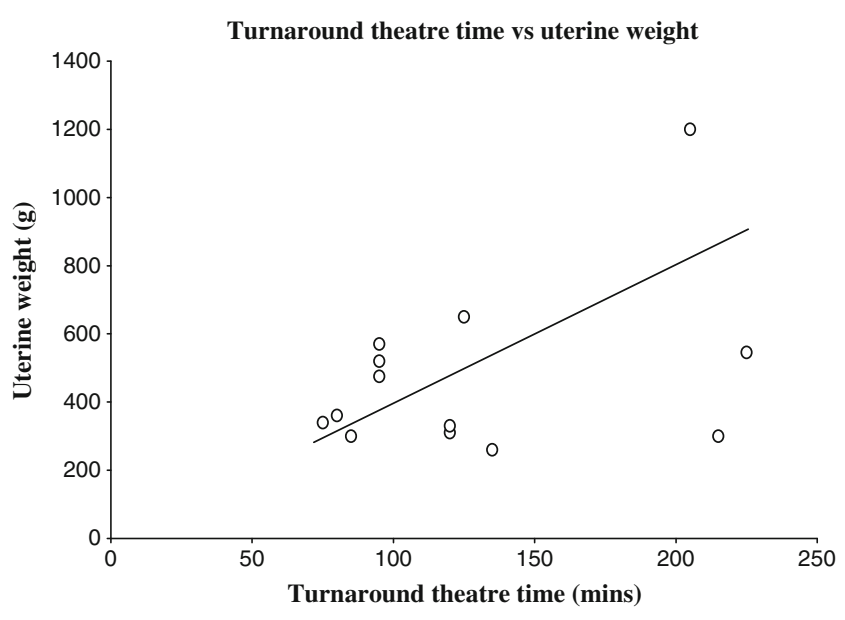

Fig. 1 Uterine weight vs duration of surgery

an outlier in the VH group whose specimen weighed $1,200 \mathrm{~g}$. Analgesia requirements and length of inpatient stay were significantly lower in the $\mathrm{VH}$ group (2.41 vs 4.1 days, $p<0.05$ ) (Table 2). Nine of the 12 TAH patients required intramuscular opioids postoperatively compared to only one in the VH group.

Serious postoperative morbidity was minimal in both groups: in the VH group, two women had pyrexia $\left(>38^{\circ} \mathrm{C}\right)$ postoperatively which resolved within $24 \mathrm{~h}$ with antibiotics, and the patient who had the 1,200-g uterus removed required two units of blood for blood transfusion.

\section{Conclusion}

Hysterectomy remains one of the commonest gynaecological operations, and the Cochrane review on the subject [13] concluded (on the basis of safety, reduced postoperative pain, shortened length of stay and higher patient satisfaction) that VH should be performed in preference to TAH, and if not possible, then a laparoscopically assisted approach may then be used. Furthermore, both Harry Reich and Ray Garry, pioneers of laparoscopic hysterectomy, agreed that "evidence based studies support the use of vaginal hysterectomy if possible over laparoscopic and abdominal hysterectomy" $[14,15]$. Despite this, there is still reluctance for gynaecologists to perform $\mathrm{VH}$, particularly in the absence of prolapse and when the uterine size exceeds 12 weeks. In fact, only $15 \%$ of hysterectomies for fibroids in the USA [16] were performed vaginally, although many authors have now reported successful vaginal removal of enlarged uteri of up to 20 weeks $[8,9]$ using techniques such as bisection, Lash intramyometrial coring, vaginal myomectomy and wedge resection.

Stovall and colleagues were the first to describe the concept of medically debulking the enlarged uterus to facilitate VH and were able to show a success rate of $70 \%$ for uteri between 14 and 18 weeks. When translated in to cost analyses, significant potential savings could be made, which would easily compensate for the cost of preoperative $\mathrm{GnRH}$ analogues expenditure [17]. Previous costing by Johns and colleagues from the USA [18] indicated that the average hospital charge for VH was US $\$ 700$ less than TAH (US $\$ 5,869$ vs $\$ 6,552$ ) while more contemporaneous data from the UK suggest similar reimbursement tariffs for both $\mathrm{VH}$ and TAH but more net profit with the former because of the shorter duration of inpatient stay.

While laparoscopy is a useful adjunct to $\mathrm{VH}$ when extensive adhesiolysis is contemplated or when there is suspected adnexal pathology, we concur with previous authors $[2,8,10]$ that laparoscopic assistance is not otherwise necessary for the vaginal removal of a moderately enlarged uterus.

Our study corroborates the previous findings that the neoadjuvant use of GnRH analogues can help facilitate vaginal hysterectomies in moderately large uteri and further demonstrates positive advantages compared to a cohort of patients with similar uterine size at surgery who underwent TAH. We admit that our case control series is neither large (12 women in each group) nor randomised and thus can be subject to type II bias. We are also aware that many exceptional vaginal surgeons are able to remove large uteri even without the use of GnRH analogues. Our study simply seeks to suggest that medical debulking using $\mathrm{GnRH}$ analogues can convert an abdominal to a potentially safe $\mathrm{VH}$ and is a simple and cost-effective way through which an "average" gynaecologist can improve skill and confidence in attempting the vaginal route. We feel that in the
Table 2 Peri- and postoperative outcome measures

NS not significant

${ }^{*} p<0.05$ is taken to infer statistical significance

\begin{tabular}{llll}
\hline Outcome measure & $\begin{array}{l}\text { VH }(n=12) \\
\text { Median (range) }\end{array}$ & $\begin{array}{l}\text { TAH }(n=12) \\
\text { Median (range) }\end{array}$ & $p$ value* \\
\hline Theatre turnover time (min) & $153.7(80-225)$ & $85(50-170)$ & 0.01 \\
Estimated blood loss (ml) & $629(200-1,600)$ & $422(100-700)$ & NS \\
Histological uterine weight $(\mathrm{g})$ & $580(475-1,200)$ & $609(450-1,218)$ & NS \\
Length of stay (days) & $2(1-5)$ & $3.5(3-9)$ & 0.02 \\
Postoperative pyrexia $>38^{\circ} \mathrm{C}$ & 2 & 0 & $\mathrm{NS}$ \\
Transfusion & 1 & 0 & $\mathrm{NS}$ \\
\hline
\end{tabular}


first year of our study, size regression achieved with goserelin gave us the confidence that VH for the "bulky" uteri is possible and motivated us to attempt removal by the vaginal route unless otherwise contraindicated. Through deliberate effort and building on experience as a result of this study, both senior authors have been able to remove progressively larger uteri so much so that analogues are currently used only for trial of $\mathrm{VH}>20$ weeks or to effect amenorrhoea in order to maximise preoperative haemoglobin.

There is therefore little doubt that with sufficient impetus, motivation and training, units can increase their vaginal hysterectomy rates for non-prolapsing uteri from under $40 \%$ to nearly $100 \%$ over a period of a few years [10].

Acknowledgements The authors are indebted to the medical writings of Mr. A. Magos, Mr. R. Varma and Professor S. Sheth in stimulating their interest in vaginal hysterectomy for the larger nondescending uteri.

Declaration of interest The authors report no conflicts of interest. The authors alone are responsible for the content and writing of the paper.

\section{References}

1. Harmanli OH, Byun S, Dandolu V, Gaughan JP, Grody MHT (2006) Vaginal hysterectomy for the enlarged uterus. Gynecol Obstet Invest 6:4-8

2. Unger JB (1999) Vaginal hysterectomy for the woman with a moderately enlarged uterus weighing 200 to 700 grams. Am J Obstet Gynecol 180(6 Pt 1):1337-1344

3. Harmanli OH, Gentzler CK, Byun S, Dandolu MH, Grody T (2004) A comparison of abdominal and vaginal hysterectomy for the large uterus. Int J Gynaecol Obstet 87(1):19-23

4. Switala I, Cosson M, Lanvin D, Querleu D, Crepin G (1998) Is vaginal hysterectomy important for large uterus of more than 500 g? Comparison with laparotomy. J Gynecol Obstet Biol Reprod (Paris) 27(6):585-592
5. Kovac SR (2000) Hysterectomy outcomes in patients with similar indications. Obstet Gynecol 95:787-793

6. Doucette RC, Sharp HT, Alder SC (2001) Challenging generally accepted contraindications to vaginal hysterectomy. Am J Obstet Gynecol 184(7):1386-1389, discussion 1390-1

7. Synder TE, Stovall TG (2002) Use of gonadotrophin releasing hormone agonist before hysterectomy. In: Sheth S, Studd J (eds) Vaginal hysterectomy. Martin Dunitz, London, pp 111-127, Chapter 10

8. Magos A, Bournas N, Sinha R, Richardson RE, O'Connor H (1996) Vaginal hysterectomy for the large uterus. BJOG 103 (3):246-251

9. Sahin Y (2007) Vaginal hysterectomy and oophorectomy in women with 12-20 weeks' size uterus. Acta Obstet Gynecol Scand 86(11):1359-1369

10. Varma R, Tahseen S, Loukugamage AU, Kunde D (2001) Vaginal route as the norm when planning hysterectomy for benign conditions: change in practice. Obstet Gynecol 97:613-616

11. Vessey MP, Villard-Mackintosh L, McPherson K, Coulter A, Yeates D (1992) The epidemiology of hysterectomy: findings in a large cohort study. BJOG 99:402-407

12. Stovall TG, Summit RL Jr, Washburn SA, Ling FW (1994) Gonadotropin-releasing hormone agonist use before hysterectomy. Am J Obstet Gynecol 170(6):1744-1748, discussion 1748-51

13. Nieboer TE, Johnson N, Lethaby A, Tavender E, Curr E, Garry R, van Voorst S, Mol BW, Kluivers KB (2009) Surgical approach to hysterectomy for benign gynaecological disease. Cochrane Database Syst Rev 8(3):CD003677

14. Reich H (2007) Total laparoscopic hysterectomy: indications, techniques and outcomes. Curr Opin Obstet Gynecol 19:337-344

15. Garry R (2009) The best way to determine the best way to undertake a hysterectomy (commentary). BJOG 116:473-477

16. Lepine LA, Hillis SD, Marchbanks PA, Koonin LM, Morrow B, Kieke BA et al (1997) Hysterectomy surveillance-United States 1980-93. CDC Surveillance summaries, August 8, 1997. MMWR Morb Mortal Wkly Rep 1997, 46(SS4):1-15

17. Bradham DD, Stovall TG, Thompson CD (1995) Use of GnRH agonist before hysterectomy: a cost simulation. Obstet Gynecol 85 (3):401-406

18. Johns DA, Carrera B, Jones J, DeLeon F, Vincent R, Safely C (1995) The medical and economic impact of laparoscopically assisted vaginal hysterectomy in a large metropolitan not for profit hospital. Am J Obstet Gynecol 172:1709-1719 